\title{
IDENTIFIKASI TELUR SOIL TRANSMITTED HELMINTHS PADA SAYURAN KUBIS, KEMANGI, DAN SELADA DI PASAR TRADISIONAL DAN PASAR MODERN DI KOTA JAMBI
}

\author{
Fenny Merselly, Hanina, Mirna Marhami Iskandar \\ Fakultas Kedokteran dan IImu Kesehatan Universitas Jambi \\ Corresponding author email: fennymerselly0@gmail.com
}

\begin{abstract}
Factors that cause contamination from STH eggs include consuming vegetables in raw, unwashed, and not cooked properly. The purpose of this study was to determine the ratio of STH eggs found in traditional and modern markets in Jambi City and to educate Indonesians who have a habit of consuming vegetables in raw conditions. This type of research was a descriptive study with a cross-sectional observational study design. The subjects of this study were cabbage, basil, and lettuce from 5 traditional markets and 5 modern markets in Jambi City which were identified using the sedimentation method. Of the 104 total samples examined, it were found that 14 positive samples (13.46\%) were contaminated by STH eggs from traditional markets and 5 positive samples (4.81\%) from modern markets. The types of STH eggs were 17 samples of Ascaris lumbricoides eggs (16.36\%) and 2 samples of Trichuris trichiura eggs (1.92\%).
\end{abstract}

Keywords: Soil Transmitted Helminths (STH) eggs, cabbage (Brasicca oleracea), basil (Ocimum basilicum), lettuce (Lactuca sativa), traditional market, modern market

\begin{abstract}
Abstrak
Faktor yang menyebabkan kontaminasi dari telur STH diantaranya dengan mengkonsumsi sayuran dalam kondisi mentah, tidak dicuci, dan tidak dimasak dengan sempurna. Tujuan dari penelitian ini untuk mengetahui perbandingan telur STH yang ditemukan pada pasar tradisional dan pasar modern di Kota Jambi dan untuk mengedukasi masyarakat Indonesia yang memiliki kebiasaan mengkonsumsi sayuran dalam kondisi mentah. Jenis penelitian ini adalah penelitian deskriptif dengan desain studi cross-sectional observasional. Subjek penelitian ini adalah sayuran kubis, kemangi, dan selada dari 5 pasar tradisional dan 5 pasar modern di Kota Jambi yang diidentifikasi dengan menggunakan metode sedimentasi. Dari 104 total sampel yang diperiksa, ditemukan jumlah sampel yang positif terkontaminasi telur STH sebanyak 14 sampel positif $(13,46 \%)$ dari pasar tradisional dan 5 sampel positif $(4,81 \%)$ dari pasar modern. Jenis telur STH yang ditemukan adalah telur Ascaris lumbricoides sebanyak 17 sampel (16,36\%) dan telur Trichuris trichiura sebanyak 2 sampel $(1,92 \%)$.
\end{abstract}

Kata Kunci: telur Soil Transmitted Helminths, kubis (Brasicca oleracea), kemangi (Ocimum basilicum), selada (Lactuca sativa), pasar tradisional, pasar modern 


\section{METODE}

Penelitian ini merupakan penelitian deskriptif dengan desain penelitian yang digunakan adalah studi cross-sectional observasional. Penelitian ini dilaksanakan dalam rentang waktu dari 16 september 2020 - 16 oktober 2020. Jumlah sampel yang digunakan dalam penelitian ini adalah 104 sampel kubis, kemangi, dan selada yang berasal dari 5 pasar tradisional dan 5 pasar modern di Kota Jambi. Besar sampel ditentukan dengan menggunakan Teknik cluster sampling berdasarkan pada lima kecamatan yang ada di Kota Jambi yaitu kecamatan Pasar Jambi, Jelutung, Kota Baru, Jambi Timur, dan Jambi Selatan. Identifikasi telur STH pada sayuran kubis, kemangi, dan selada dilakukan dengan menggunakan metode sedimentasi. Bahan yang digunakan adalah sayuran kubis, sayuran kemangi, sayuran selada, larutan $\mathrm{NaOH} \quad 0,2 \%$, larutan eosin $2 \%$, dan aquadest. Alat yang digunakan adalah sentrifuge, tabung sentrifuge, mikroskop, object glass, cover glass, rak tabung, pipet tetes, beaker glass, gelas ukur, batang pengaduk, neraca Ohaus, hand scoon steril, kantong plastik, dan kertas label. Prosedur kerja dimulai dengan merendam $50 \mathrm{gr}$ masing-masing potongan sampel sayuran dalam 500 ml larutan $\mathrm{NaOH}$ 0,2\% selama 30 menit. Kemudian sampel sayuran diaduk hingga merata lalu sayuran dikeluarkan dan didiamkan selama 1 jam. Diambil air yang berada dibagian bawah beaker glass beserta endapannya sebanyak 5-10 ml menggunakan pipet tetes kemudian dimasukkan ke dalam tabung sentrifuge. Hasil endapan disentrifugasi dengan kecepatan $1500 \mathrm{rpm}$ selama 5 menit. Setelah supernatant dibuang, endapan bagian bawah diambil untuk diperiksa secara mikroskopik dengan pembesaran 10x dan 40x. Data disajikan dalam bentuk tabulasi.

\section{HASIL DAN PEMBAHASAN}

Dari masing-masing pasar, diperoleh total sampel sebanyak 12 sampel yaitu 4 sampel kubis, 4 sampel kemangi, dan 4 sampel selada. Tetapi terdapat empat pasar modern yang tidak menyediakan kemangi untuk dijual sehingga pada penelitian ini hanya digunakan kemangi dari 1 pasar modern yaitu Jambi Town Square dan 5 pasar tradisional. Sehingga, total sampel yang telah diperiksa pada penelitian ini sebanyak 104 sampel sayuran dengan menggunakan metode sedimentasi.

Tabel 1. Daftar Sumber Subjek Penelitian

\begin{tabular}{ll}
\hline Pasar Tradisional & \multicolumn{1}{c}{ Pasar Modern } \\
\hline Angso Duo & WTC Batanghari \\
Hongkong & Jambi Prima Mall \\
Mama & Jambi Town Square \\
Talang Banjar & Meranti Swalayan \\
Pasar Kito & Transmart \\
\hline
\end{tabular}

Tabel 1 menunjukkan daftar sumber subjek penelitian yang terlibat dalam pengambilan sampel penelitian dengan metode cluster sampling.

Berdasarkan hasil identifikasi telur STH pada sayuran kubis, kemangi, dan selada di pasar tradisional dan pasar modern di Kota Jambi didapatkan hasil sebagai berikut: 
MEDIC, Volume 4, nomor 1, April 2021, Hal: 131- 139 Fenny Merselly, dkk. Identifikasi ...

Tabel 2. Distribusi Frekuensi Kontaminasi Telur STH Berdasarkan Jenis Pasar

\begin{tabular}{lcccccc}
\hline \multirow{2}{*}{ Jenis Pasar } & \multicolumn{3}{c}{ Hasil } & \multicolumn{2}{c}{ Total Sampel } \\
\cline { 2 - 6 } & \multicolumn{2}{c}{ Positif } & \multicolumn{2}{c}{ Negatif } & \multicolumn{2}{c}{} \\
\cline { 2 - 6 } Tradisional & $\mathbf{n}$ & $\%$ & $\mathbf{n}$ & $\%$ & $\mathbf{n}$ & $\%$ \\
\hline Modern & 14 & 13,46 & 46 & 44,23 & 60 & 57,69 \\
\hline Total & 5 & 4,81 & 39 & 37,50 & 44 & 42,31 \\
\hline
\end{tabular}

Tabel 2 menunjukkan distribusi frekuensi kontaminasi telur STH berdasarkan jenis pasar. Dari 104 sampel yang telah diperiksa, ditemukan jumlah sampel yang positif terkontamiasi STH sebanyak 19 sampel (18,27\%) dari pasar tradisional dan pasar modern di Kota Jambi. Pada pasar tradisional terdapat 14 sampel positif $(13,46 \%)$ dan 46 sampel negatif $(44,23 \%)$. Sedangkan pada pasar modern terdapat 5 sampel positif $(4,81 \%)$ dan 39 sampel negatif $(37,50 \%)$.

Tabel 3. Distribusi Frekuensi Kontaminasi Telur STH Berdasarkan Jenis Sayuran

\begin{tabular}{lcccccc}
\hline \multirow{2}{*}{ Jenis Sayur } & \multicolumn{3}{c}{ Hasil } & \multicolumn{2}{c}{ Total Sampel } \\
\cline { 2 - 6 } & \multicolumn{2}{c}{ Positif } & \multicolumn{2}{c}{ Negatif } & \multicolumn{2}{c}{} \\
\cline { 2 - 6 } & $\mathbf{n}$ & $\%$ & $\mathbf{n}$ & $\%$ & $\mathbf{n}$ & $\%$ \\
\hline Kubis & 2 & 1,92 & 38 & 36,54 & 40 & 38,46 \\
\hline Kemangi & 10 & 9,62 & 14 & 13,46 & 24 & 23,08 \\
\hline Selada & 7 & 6,73 & 33 & 31,73 & 40 & 38,46 \\
\hline Total & 19 & 18,27 & 85 & 81,73 & 104 & 100 \\
\hline
\end{tabular}

Tabel 3 menunjukkan distribusi frekuensi kontaminasi telur STH berdasarkan jenis sayuran. Dari 19 sampel sayuran yang positif terkontaminasi, sampel positif pada sayuran kubis sebanyak 2 sampel (1,92\%) dan negatif 38 sampel $(36,54 \%)$, dimana sebayak 1 sampel (0,96\%) dari pasar tradisional dan sebanyak 1 sampel $(0,96 \%)$ dari pasar modern. Sampel positif pada sayuran kemangi ditemukan sebanyak 10 sampel $(9,62 \%)$ dan negatif 14 sampel $(13,46 \%)$, dimana sebanyak 10 sampel $(9,62 \%)$ dari pasar tradisional dan 0 sampel (0\%) dari pasar modern. Sampel positif pada sayuran selada sebanyak 7 sampel $(6,73 \%)$ dan negatif 33 sampel $(31,73 \%)$, dimana 3 sampel $(2,89 \%)$ dari pasar tradisional dan 4 sampel $(3,85 \%)$ dari pasar modern. 
Tabel 4. Distribusi Frekuensi Jenis Telur STH Berdasarkan Jenis Pasar

\begin{tabular}{lcccc}
\hline \multirow{2}{*}{ Jenis Pasar } & \multicolumn{2}{c}{ Telur } & \multicolumn{3}{c}{ Telur } \\
& \multicolumn{2}{c}{ A. lumbricoides } & $\%$ & \multicolumn{2}{c}{ T. trichiura } \\
\cline { 2 - 6 } & $\mathbf{n}$ & 12,5 & 1 & $\%$ \\
\hline Tradisional & 13 & 3,85 & 1 & 0,96 \\
\hline Modern & 4 & & & 0,96 \\
\hline
\end{tabular}

Tabel 4 menunjukkan distribusi frekuensi jenis telur STH berdasarkan jenis pasar. Pada pasar tradisional, ditemukan jenis telur A. lumbricoides sebanyak 13 sampel $(12,5 \%)$ dan telur T. trichiura sebanyak 1 sampel (0,96\%). Pada pasar modern, ditemukan jenis telur $A$. lumbricoides sebanyak 4 sampel $(3,85 \%)$ dan telur $T$. trichiura sebanyak 1 sampel $(0,96 \%)$.

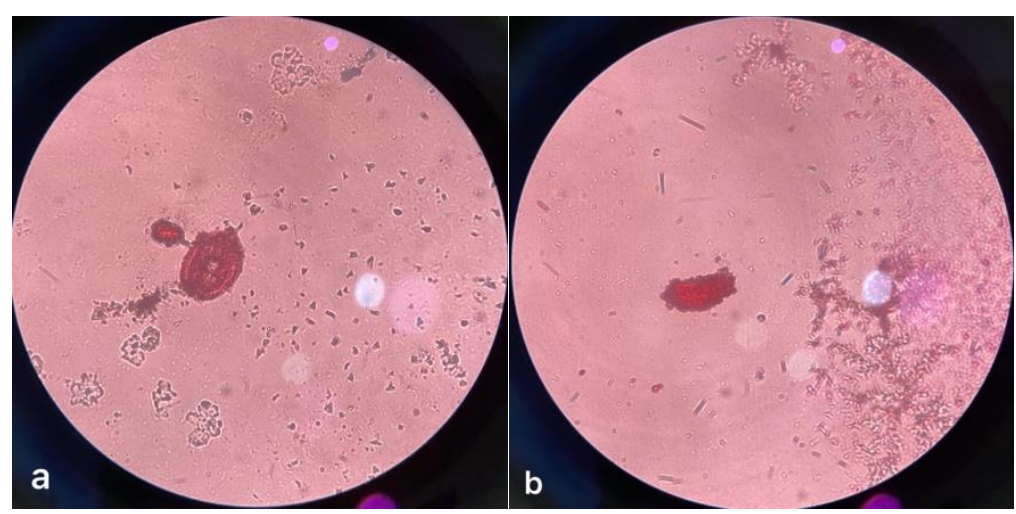

Gambar 1. Telur A. lumbricoides fertilized egg (a) dan infertilized egg (b) pada pembesaran lensa objektif $40 \mathrm{x}$

$\begin{array}{lll}\text { Gambar } 1 \text { menunjukkan telur } A . & \text { terdiri dari tiga lapis, lapisan luar terdiri dari } \\ \text { lumbricoides yang ditemukan pada } & \text { bahan albuminoid yang bergerigi, lapisan } \\ \text { pemeriksaan mikroskopik dengan } & \text { tengah transparan terbuat dari bahan } \\ \text { pembesaran lensa objektif } 40 x \text { yaitu telur } A . & \text { glikogen, dan yang paling dalam adalah } \\ \text { lumbricoides yang dibuahi (fertilized egg) (a) } & \begin{array}{l}\text { lapisan lipoidal. Sedangkan telur } A . \\ \text { dan yang tidak dibuahi (infertilized egg) (b). }\end{array} \\ \text { Telur } A \text { lumbricoides yang infertilized egg berbentuk } \\ \text { berbentuk oval dengan terdapat lapisan luar }\end{array}$




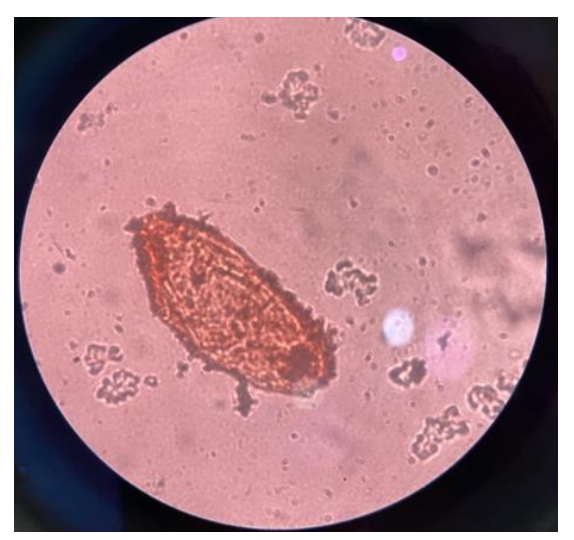

Gambar 4.2 Telur T. trichiura pada pembesaran lensa objektif 40x

Gambar 2 menunjukkan telur T. trichiura yang ditemukan pada pemeriksaan mikroskipik dengan pembesaran lensa objektif 40x. Telur berbentuk khas seperti biji melon berwarna coklat dan memiliki dua kutub yang menonjol. 2,10

Tabel 5. Distribusi Frekuensi Jenis Telur STH Berdasarkan Jenis Sayuran

\begin{tabular}{lcccc}
\hline \multirow{2}{*}{ Jenis Sayuran } & \multicolumn{2}{c}{ Telur } & \multicolumn{2}{c}{ Telur } \\
& \multicolumn{2}{c}{$\boldsymbol{A}$. Iumbricoides } & $\%$ & \multicolumn{2}{c}{ T. trichiura } \\
\cline { 2 - 5 } & $\mathbf{n}$ & 0 & $\mathbf{n}$ & $\%$ \\
\hline Kubis & 0 & 9,62 & 0 & 1,92 \\
\hline Kemangi & 10 & 6,73 & 0 & 0 \\
\hline Selada & 7 & & & 0 \\
\hline
\end{tabular}

Tabel 5 menunjukkan distribusi frekuensi jenis telur STH berdasarkan jenis sayuran. Telur A. lumbricoides ditemukan pada sayuran kubis sebanyak 0 sampel $(0 \%)$, pada sayuran kemangi sebanyak 10 sampel $(9,62 \%)$, dan pada sayuran selada sebanyak 7 sampel (6,73\%). Telur $T$. trichiura ditemukan pada sayuran kubis sebanyak 2 sampel (1,92\%), pada sayuran kemangi sebanyak 0 sampel $(0 \%)$, dan pada sayuran selada sebanyak 0 sampel $(0 \%)$. 
Tabel 6. Distribusi Frekuensi Kontaminasi pada Sampel Penelitian

\begin{tabular}{|c|c|c|c|c|c|c|}
\hline & \multicolumn{4}{|c|}{ Jenis Telur STH } & \multirow{2}{*}{\multicolumn{2}{|c|}{ Total }} \\
\hline & \multicolumn{2}{|c|}{ A. lumbricoides } & \multicolumn{2}{|c|}{ T. trichiura } & & \\
\hline & $\mathbf{n}$ & $\%$ & $\mathbf{n}$ & $\%$ & $\mathbf{n}$ & $\%$ \\
\hline Pasar Tradisional & & & & & 14 & 13,46 \\
\hline Kubis & 0 & 0 & 1 & 0,96 & & \\
\hline Kemangi & 10 & 9,62 & 0 & 0 & & \\
\hline Selada & 3 & 2,89 & 0 & 0 & & \\
\hline Pasar Modern & & & & & 5 & 4,81 \\
\hline Kubis & 0 & 0 & 1 & 0,96 & & \\
\hline Kemangi & 0 & 0 & 0 & 0 & & \\
\hline Selada & 4 & 3,85 & 0 & 0 & & \\
\hline Total & 17 & 16,36 & 2 & 1,92 & 19 & 18,27 \\
\hline
\end{tabular}

Tabel 6 menunjukkan distribusi frekuensi kontaminasi pada sampel penelitian. Ditemukan 19 sampel sayuran yang positif terkontaminasi STH pada kedua jenis pasar. Pada pasar tradisional didapatkan total sayuran yang terkontaminasi sebanyak 14 sampel (13,46\%) dengan telur $A$. lumbricoides yang ditemukan pada sayuran kubis sebanyak 0 sampel (0\%), pada sayuran kemangi sebanyak 10 sampel $(9,62 \%)$, dan pada sayuran selada sebanyak 3 sampel (2,89\%). Sedangkan telur $T$. trichiura yang ditemukan pada sayuran kubis sebanyak 1 sampel $(0,96 \%)$, pada sayuran kemangi sebanyak 0 sampel $(0 \%)$, dan pada sayuran selada sebanyak 0

Berdasarkan hasil penelitian yang telah disajikan di atas, jenis telur STH yang ditemukan pada sampel kubis, kemangi, dan selada di pasar tradisional dan pasar modern adalah telur $A$. lumbricoides dan telur T. trichiura. Hal ini disebabkan karena pada ketiga jenis sayuran yang diteliti memiliki morfologi yang mudah terkontaminasi oleh telur STH. Sayuran sampel (0\%). Pada pasar modern didapatkan total sayuran yang terkontaminasi sebanyak 5 sampel $(4,81 \%)$ dengan telur $A$. lumbricoides yang ditemukan pada sayuran kubis sebanyak 0 sampel $(0 \%)$, pada sayuran kemangi sebanyak 0 sampel (0\%), dan pada sayuran selada sebanyak 4 sampel (3,85\%). Telur $T$. trichiura yang ditemukan pada sayuran kubis sebanyak 1 sampel $(0,96 \%)$, pada sayuran kemangi sebanyak 0 sampel $(0 \%)$, dan pada sayuran selada sebanyak 0 sampel $(0 \%)$. Sehingga total kontaminasi telur STH jenis $A$. lumbricoides sebanyak 17 sampel $(16,36 \%)$ dan jenis T. trichiura sebanyak 2 sampel $(1,92 \%)$.

kubis yang tumbuh dekat dengan permukaan tanah dengan struktur daun kubis yang berlekuk-lekuk dan berlapis, kemangi memiliki daun dengan permukaan yang berbulu halus, dan selada memiliki bentuk daun yang polimorf tersusun dalam roset padat sehingga dapat mempengaruhi tingginya kontaminasi telur STH. ${ }^{11-13}$ 
Perbedaan kontaminasi pada ketiga jenis sayuran pada pasar tradisional dan pasar modern ini disebabkan oleh beberapa faktor yang mempengaruhinya. Sumber sayuran dari kedua jenis pasar memiliki perlakukan pasca panen yang bisa jadi berbeda. ${ }^{14}$ Di pasar tradisional, sumber sayuran langsung dari petani sayuran yang didistribusikan ke pasar dengan perlakuan seadanya. Sedangkan di pasar modern, sumber sayuran melalui proses seleksi terlebih dahulu oleh pemasok sayur di pasar modern dengan melalui perlakuan khusus untuk menjaga higienitas dari sayuran itu sendiri. Standard penanaman dan proses pasca panen sayuran yang dijual di pasar tradisional dan pasar modern dapat menyebabkan perbedaan besarnya kontaminasi. ${ }^{14,15}$ Faktor selanjutnya adalah perbedaan cara penyimpanan. Bila tempat penyimpanan sayuran tersebut lembab dan tidak bersih bisa menjadi faktor penyebab telur STH bertahan dan berkembang menjadi bentuk infektif. ${ }^{16}$ Faktor lainnya adalah kondisi pasar tradisional yang berbeda dengan pasar modern. Pada pasar tradisional, kondisi pasar yang dijadikan tempat pengambilan sampel cenderung lembab, kotor, dan terbuka, penempatan sayuran diletakkan seadanya yang didekatkan dengan jenis sayuran yang lainnya sehingga dapat memungkinkan kontaminasi silang dari sayuran yang satu dengan yang lainnya. Sedangkan pada pasar modern, kondisi pasar yang dijadikan tempat pengambilan sampel terlihat bersih, sayuran diletakkan pada lemari pendingin, dan adanya plastik pembungkus antar sayuran sehingga dapat mencegah kontaminasi silang.

Pada penelitian ini, dari 19 jumlah sampel yang positif terdapat 19 jumlah telur STH yang mengkontaminasi sayuran pada kedua jenis pasar. Dimana kontaminasi oleh telur $A$. lumbricoides lebih besar daripada telur $T$. trichiura dan tidak ditemukan telur Hookworm. Besarnya kontaminasi oleh telur A. lumbricoides ini salah satunya bisa disebabkan oleh faktor produksi telur yang sangat tinggi, dimana cacing $A$. lumbricoides betina dapat memproduksi 200.000 telur per hari dibandingkan dengan cacing betina $T$. trichiura yang hanya menghasilkan 300020.000 telur per hari, sehingga dapat menjadi faktor penyebab telur $A$. lumbricoides lebih banyak ditemukan pada penelitian ini. ${ }^{4}$ Tidak ditemukannya telur Hookworm pada penelitian ini bisa disebabkan oleh beberapa faktor seperti jenis tanah, dimana cacing Hookworm dapat tumbuh optimum pada lingkungan yang mengandung pasir. Hal ini disebabkan karena pasir memiliki berat jenis yang lebih besar daripada air, sehingga telurnya akan terlindung dari sinar matahari. Selain itu, tidak ditemukannya telur Hookworm ini bisa disebabkan karena faktor waktu matangnya telur Hookworm itu sendiri yaitu berkisar 1-2 hari dengan suhu optimum $23-33^{\circ} \mathrm{C} . .^{17,18}$

Hasil penelitian ini sejalan dengan penelitian sebelumnya yang dilakukan di Medan, penelitian tersebut menjelaskan bahwa adanya kontaminasi telur STH pada sayuran kubis. $^{6}$ Penelitian lain yang menunjukkan hal yang sama dapat dilihat dari penelitian yang dilakukan di Jombang yang menunjukkan adanya kontaminasi 
telur STH pada sayuran kemangi. ${ }^{7}$ Hasil penelitian yang sama juga dilakukan di Surakarta yang menunjukkan adanya kontaminasi telur STH pada sayuran selada. ${ }^{13}$

Kesimpulan dari penelitian ini adalah sayuran kubis, kemangi, dan selada yang dijual di pasar tradisional dan pasar modern di Kota Jambi positif terkontaminasi telur STH dengan jumlah kontaminasi telur STH sebanyak 19 sampel sayuran. Jenis telur STH yang ditemukan adalah telur $A$. lumbricoides dan telur T. trichiura.

\section{KESIMPULAN}

Kesimpulan dari penelitian ini adalah sayuran kubis, kemangi, dan selada yang dijual di pasar tradisional dan pasar modern di Kota Jambi positif terkontaminasi telur STH dengan jumlah kontaminasi telur STH sebanyak 19 sampel sayuran. Jumlah sampel yang positif terkontaminasi telur
STH berdasarkan jenis pasar ditemukan lebih banyak pada pasar tradisional daripada pasar modern. Jenis telur STH yang ditemukan pada penelitian ini yaitu telur A. lumbricoides dan telur T. trichiura, dimana telur $A$. lumbricoides yang ditemukan lebih banyak daripada telur $T$. trichiura.Jenis sayuran yang terkontaminasi telur STH pada penelitian ini banyak ditemukan pada sayuran kemangi.

Penelitian ini memiliki keterbatasan yaitu tidak adanya kriteria khusus untuk jenis kios pada pasar yang digunakan sebagai tempat pengambilan sampel penelitian sehingga tidak adanya keseragaman sumber sampel secara merata dikarenakan kondisi ketersediaan sayuran yang terbatas, sehingga ada sampel sayuran yang diambil dari satu kios dan ada sampel sayuran yang di ambil dari berbagai kios yang berbeda.

\section{DAFTAR PUSTAKA}

1. Alemu, G., Mama, M., Misker, D., et al. Parasitic Contamination of Vegetables Marketed in Arba Minch Town, Southern Ethiopia. BMC Infect Dis; 2019;19:410.

2. Merdekawati, Diah. Peran Ibu terhadap Pencegahan Ascaris Anak Prasekolah Wilayah Kerja Puskesmas Tahtul Yaman Kota Jambi; 2017.

3. Ariyadi, Bambang. Gambaran Kejadian Kecacingan pada Murid Sekolah Dasar di Kelurahan Tanjung Johor Kecamatan Pelayangan Kota Jambi 2015; 2016.

4. Soedarto. Buku Ajar Parasitologi Kedokteran. Jakarta: Sagung Seto; 2011.

5. Departemen Kesehatan RI. Peraturan Menteri Kesehatan Republik Indonesia Nomor 15 Tahun 2017 tentang Penanggulangan Cacingan. Jakarta: Kemenkes RI; 2017.

6. Fransisca, M. Perbedaan Angka Kejadian Parasit Intestinal pada Kubis (Brassica oleracea) yang Dijual di Pasar Tradisional dan Pasar Modern di Kota Medan. [Skripsi]. Fakultas Kedokteran: Universitas Sumatera Utara; 2017.

7. Agni, F. Identifikasi Telur Cacing STH (Soil Transmitted Helminth) pada Daun Kemangi; 2018.

8. Putri, Ulfadiyah., Hanina., \& Amelia Dwi Fitri. Kontaminasi Soil Transmitted Helminths pada Sayuran Kubis dan Selada di Pasar Tradisional Kota Jambi; 2020.

9. Noon, J. B. \& Aroian, R. V. Recombinant Subunit Vaccines for Soil Transmitted Helminths. Parasitology. Cambridge University Press; 2017;144(14):1845-70.

10. Safar, R. Parasitologi Kedokteran: Protozoologi, Entomologi, dan Helmintologi. Bandung: Yrama Widya; 2010. 
MEDIC, Volume 4, nomor 1, April 2021, Hal: 131- 139 Fenny Merselly, dkk. Identifikasi ...

11. Mutianingsih, W. E. Identifikasi Telur Soil Transmitted Helminth (STH) dengan Metode Flotasi Selada dan Kol yang Disajikan Pedagang Kaki Lima Alun-Alun Ciamis Tahun 2016; 2016.

12. Meisaraswati, K. D. Perbedaan Kontaminasi Nematoda Usus Golongan Soil Transmitted Helminths pada Sayuran Kemangi dengan Perlakuan Perendaman Larutan $\mathrm{NaOH} 0,2 \%$ dan Deterjen Cair 10\%; 2018.

13. Musriyati. Identifikasi Ookista Toxoplasma gondii pada Sayuran Selada (Latuca sativa) yang Disajikan Pedagang Burger Kaki Lima di Wilayah Surakarta; 2018.

14. Maldonade, I. R., Figueiredo, R., Riquette, R. \& Machado, E. R. Good Manufacturing Practices of Minimally Processed Vegetables Reduce Contamination with Pathogenic Microorganisms. Rev Inst Med Trop Sao Paulo; 2019;61:e14.

15. Mohamed, M. A., Siddig, E. E., Elaagip, A. H., Edris, A. M. \& Nasr, A. Parasitic Contamination of Fresh Vegetables Sold at Central Markets in Khartoum State, Sudan. Ann Clin Microbiol Antimicrob; 2016;15:17.

16. Javanmard, E., et al. Small-scale Risk Assessment of Transmission of Parasites from Wastewater Treatment Plant to Downstream Vegetable Farms. Gastroenterol Hepatol Bed Bench; 2018;11(4):352358.

17. Zulflah, A. Identifikasi Telur dan Larva Cacing Soil Transmitted Helminths (STH) pada Lalapan Daun Kemangi (Ocimum basilicum) di Jakabaring, Palembang Periode Juli 2016 - Januari 2017; 2017.

18. Febrita, E \& Pratiwi, L. Identifikasi Jenis Telur Nematoda yang Terdapat pada Sayuran; 2015. 